\title{
Investigation of autopsy results in cadavers with lead poisoning in Tehran Legal Medicine Center over 10 years
}

\author{
Fares Najari'”, Seyed Mojtaba Abolbagaei',Babak Mostafazadeh','Dorsa Najari² \\ 'Department of Legal Medicine, Faculty of Medicine, Shahid Beheshti University of Medical Sciences, Tehran, Iran \\ ${ }^{2} S c h o o l$ of Medicine, Shahid Beheshti University of Medical Sciences, Tehran, Iran
}

\author{
Received: 7 June 2020 \\ Accepted: 29 August 2020 \\ Published online: 11 September \\ 2020 \\ *Corresponding author: \\ Fares Najari; Department of Legal \\ Medicine, Faculty of Medicine, \\ Shahid Beheshti University of \\ Medical Sciences, Tehran, Iran; \\ Email: najari.hospital@sbmu.ac.ir \\ Competing interests: None. \\ Funding information: None. \\ Citation: Najari F, Abolbagaei SM \\ Investigation of autopsy results in \\ cadavers with lead poisoning in \\ Tehran Legal Medicine Center over \\ 10 years. Journal of Emergency \\ Practice and Trauma 2021; 7(1): $x-x$ \\ doi: 10.34172/jept.2020.26
}

\begin{abstract}
Objective: Due to the rapid pace of industrialization and the high prevalence of addiction, toxicity caused by heavy metals, especially lead, has become one of the major health problems associated with high morbidity and mortality. Therefore, reliable information is critical to manage this condition.

Methods: This descriptive cross-sectional study was performed on 30 cadavers, suspected of lead poisoning. The hospital records and the results of anatomical investigations were studied. Data were collected in a researcher-made questionnaire and analyzed in SPSS Version 22.

Results: The results showed a significant correlation between the pathological results of pulmonary autopsy and the duration of drug use $(P=0.01)$. Also, the pathological results of cardiac autopsy had significant correlations with age $(P=0.006)$ and blood lead level $(P=$ 0.03). Moreover, significant correlations were found between the pathological results of liver autopsy and age $(P=0.00)$, between the pathological results of brain autopsy and the route of drug administration $(P=0.01)$, and between the pathological results of kidney autopsy and age $(P=0.00)$. Most pathological changes were observed in the brain and kidney tissues. Conclusion: Lead poisoning does not cause any specific pathological changes in the liver, heart, brain, lung, or kidney tissues; however, these non-specific changes, alone or together, can lead to death.

Keywords: Lead, Organ failure, Autopsy, Cadavers
\end{abstract}

\section{Introduction}

Lead is one of the most important heavy metals, with significant toxic effects on all living organisms. It is also the most abundant heavy metal with the widest distribution in the environment. The main source of lead in the environment is vehicles, but it is also widely used in different industries $(1,2)$. As a toxic agent, it causes a wide range of lesions and abnormalities in living species, including humans. Both acute and chronic poisoning can occur through the skin, digestion, and respiration following lead distribution in soft tissues, especially the liver and the central nervous system (CNS), resulting in various manifestations, such as insomnia, hallucinations, delusions, seizures, and even death $(3,4)$.

Due to the wide application and distribution of lead, its environmental concentration is increasing in most countries, especially due to its use as an illegal drug (5). Drug abuse is one of the major public health problems in all countries, including Iran. Its prevalence is almost $1 \%$ $2 \%$ globally, which is much lower than the rates reported in Iran, especially in some rural areas, where it reaches up to $22 \%$ (6).

Today, opium is recognized as a new source of lead poisoning. Due to the widespread prevalence of traditional and industrial opium, it is more profitable for drug dealers to mix this substance with other drugs to increase the drug weight because of the high volume of lead $(7,8)$. Also, evidence shows that people who work in coal mines and printing industries, as well as painters, bus drivers, and tile workers, are at risk of complications due to lead poisoning (9). Moreover, some foods, such as vegetables and bread, as well as makeup products and toys, are categorized as other sources of lead poisoning.

Although major efforts have been made to reduce lead exposure, this source of poisoning is still one of the major health problems worldwide (10). Blood tests are commonly used for diagnosis of lead poisoning, whereas in cadavers, assay of body tissues, especially the liver, kidneys, and brain tissues, is performed through autopsy (11). Due to the lack of research on the autopsy of lead 
poisoning in Iran, we aimed to investigate lead poisoning assays in autopsy specimens.

\section{Methods}

This observational, descriptive, cross-sectional study was performed on 30 cadavers in Kahrizak Autopsy Hall (Tehran, Iran) during 2008-2018. Cadavers suspected of lead poisoning were investigated in this study. Each cadaver was fully examined for unusual manifestations. The exclusion criteria were as follows: 1) death records with underlying diseases, such as diabetes, hypertension, and coronary artery disease; 2) unidentified cases of lead poisoning; and 3) lack of documentation of lead concentration and records without anatomical results. In this study, we strictly adhered to the Helsinki Code of Ethics (1396/361), and the information files remained completely confidential.

In the examinations, findings indicative of lead poisoning included the presence of a lead line on the gums and severe cerebral edema. The brain, heart, and lung specimens were sent for pathological investigations if indicated. If the deceased was admitted to the hospital before death, his/her clinical history was requested for further inquiry.

The relatives of the deceased were interviewed to determine their occupational status and identify possible occupational exposure to lead, history of drug abuse, and route of administration (e.g., oral inhalation). Based on the information obtained from toxicology screening, clinical examinations, and supplementary studies (e.g., clinical history-taking), the cause of death was determined.

Data were analyzed using SPSS Version 22. Descriptive statistics were used to evaluate the relationships between variables. Fisher's exact test and $t$ test or its non-parametric equivalent (Mann-Whitney test) were applied for data analysis. $P$ value of 0.03 was considered statistically significant.

\section{Results}

In this study, a total of 30 cadavers with lead poisoning were investigated. Six cadavers were female, and 24 were male (age range: 32-79 years). Table 1 presents the information obtained from the medical history of cadavers.

The pathological findings of the lungs were categorized as acute (45.8\%) and chronic (54.2\%) lesions. In cadavers with acute lesions, acute respiratory distress syndrome was the major finding, whereas, in cadavers with chronic loss of type II pneumocytes, destruction of the alveolar walls and atelectasis with some degree of fibrosis were detected. Other organ findings, based on gender, are depicted in Table 2.

The distribution of the following data was not considered significant: sex, age, education, occupation, duration of drug use, initial complaints, final diagnosis based on the hospital records, hemoglobin $(\mathrm{Hb})$, alanine aminotransferase (ALT), aspartate transaminase (AST), and creatinine $(\mathrm{Cr})$ levels, systolic blood pressure, and diastolic blood pressure $(P=0.07)$. In the oral administration group, 26 (100\%) cases had lead levels $>70$ $\mathrm{mg} / \mathrm{dL}$, while $14(33.3 \%)$ cases in the inhalation group had lead levels $>70 \mathrm{mg} / \mathrm{dL}$. However, there was no significant relationship between the results of autopsy and gender $(P>0.07)$ (Figure 1 and Table 1$)$.

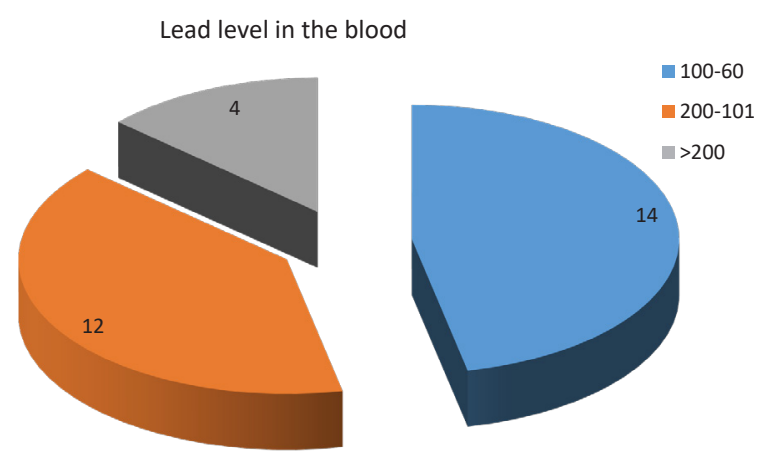

Figure 1. The blood lead levels.

Table 1. Data obtained from the medical records

\begin{tabular}{lcccc}
\hline & Min. & Max. & Mean & SD \\
\hline Age & 32 & 79 & 52.67 & 12.8 \\
Duration of consumption & 7 & 40 & 17.48 & 10.09 \\
Lead level & 60 & 477.2 & 138.3 & 91.5 \\
$\mathrm{Hb}$ & 6.9 & 15.4 & 9.7 & 2.4 \\
Urea & 2.6 & 221 & 47 & 47 \\
Creatinine & 0.5 & 3.3 & 1.2 & 0.6 \\
AST & 15 & 1126 & 134 & 235.7 \\
ALT & 10 & 1300 & 117.75 & 270.2 \\
\hline Abbreviations: Hb, hemoglobin; & AST, aspartate transaminase; ALT, alanine \\
aminotransferase. & \multicolumn{4}{l}{}
\end{tabular}

Table 2. The major findings of the evaluated organs

\begin{tabular}{|c|c|c|}
\hline Organs & Male & Female \\
\hline Heart & Myocarditis and moderate to severe arteriosclerosis $(n=15)$ & Myocarditis and moderate to severe arteriosclerosis $(n=2)$ \\
\hline Liver & $\begin{array}{l}\text { Necrosis, lymphocyte recruitment and vacuolization, and } \\
\text { hepatitis }(n=10)\end{array}$ & $\begin{array}{l}\text { Lymphocyte recruitment, } \\
\text { vacuolization, hepatitis, } \\
\text { and insignificant findings } \\
\qquad(\mathrm{n}=10)\end{array}$ \\
\hline Brain & Degenerative encephalopathy in the Purkinje cell line $(n=21)$ & Degenerative encephalopathy in the Purkinje cell line $(n=3)$ \\
\hline Kidney & $\begin{array}{l}\text { Tubulointerstitial nephritis) tubular atrophy and some degree of } \\
\text { dilation) }(n=19)\end{array}$ & Tubulointerstitial nephritis) tubular atrophy and some degree of dilation) $(n=4)$ \\
\hline
\end{tabular}


Table 3 .Confidence relation between autopsy finding and opiate

\begin{tabular}{|c|c|c|c|c|c|}
\hline Autopsy finding & Route of use & Kind of opiate & Duration of use & Age & Blood Lead Level \\
\hline Lung & $\begin{array}{l}(18) 59 \%(\text { inhalation }) P \\
\text { value }<0 / 02\end{array}$ & $\begin{array}{l}11(34 \%) \text { Traditional }) \\
P \text { value }>0 / 05\end{array}$ & $\begin{array}{l}>20 y(21) 66 \% \\
P \text { value }<0 / 01\end{array}$ & $\begin{array}{l}>50 y(24) 81 \% \\
P \text { value }<0 / 003\end{array}$ & $\begin{array}{l}<70 \mathrm{mic} / \mathrm{dl} \\
P \text { value }>0 / 05\end{array}$ \\
\hline Liver & $\begin{array}{l}23(71 \%)(\text { oral }) \\
P \text { value }<0 / 01\end{array}$ & $\begin{array}{l}11(33 \%) \text { Traditional }) \\
P \text { value }>0 / 05\end{array}$ & $\begin{array}{l}>20 y(9) 30 \% \\
P \text { value }>0 / 05\end{array}$ & $\begin{array}{l}>50(15) 50 \% \\
P \text { value }<0 / 00\end{array}$ & $\begin{array}{l}<70 \mathrm{mic} / \mathrm{dl} \\
P \text { value }>0 / 05\end{array}$ \\
\hline Heart & $\begin{array}{l}11(33 \%) \text { oral } \\
P \text { value }>0 / 05\end{array}$ & $\begin{array}{l}17 \text { (traditional) } \\
P \text { value }<0 / 04\end{array}$ & $\begin{array}{l}>20 y(8) 28 \% \\
P \text { value }>0 / 05\end{array}$ & $\begin{array}{l}>50(18) 60 \% \\
P \text {-value }<0 / 00\end{array}$ & $\begin{array}{l}>70 \mathrm{mic} / \mathrm{dl}(24) \\
P \text { value }<0 / 003)\end{array}$ \\
\hline Brain & $\begin{array}{l}27(93) \%(\text { oral }) \\
P \text { value }<0 / 01\end{array}$ & $\begin{array}{l}28(95 \%) \text { (traditional) } \\
P \text { value }<0 / 003\end{array}$ & $\begin{array}{l}>20 y(5) 15 \% \\
P \text { value }>0 / 05\end{array}$ & $\begin{array}{l}>50(10) 34 \% \\
P \text { value }>0 / 05\end{array}$ & $\begin{array}{l}>70 \mathrm{mic} / \mathrm{dl}(24) \\
P \text { value }<0 / 003)\end{array}$ \\
\hline Kidney & $\begin{array}{l}6(35 \% \text { oral } \\
P \text { value }>0 / 05\end{array}$ & $\begin{array}{l}9(30 \%) \text { Traditional }) \\
P \text { value }>0 / 05\end{array}$ & $\begin{array}{l}>20 y(30) 100 \% \\
P \text { value }<0 / 0003)\end{array}$ & $\begin{array}{l}>50(4) 14 \% \\
P \text { value }>0 / 05\end{array}$ & $\begin{array}{l}>70 \mathrm{mic} / \mathrm{dl}(27) P \text { value } \\
<0 / 002)\end{array}$ \\
\hline
\end{tabular}

The distribution of cardiac findings was significantly different in terms of blood lead level and age $(P<0.05)$, indicating cellular changes in the heart with advancing age or increase of the blood lead level. Also, the distribution of the examination results of lead toxicity in the brain was significantly different in terms of the route of administration $(P=0.05)$. However, regarding the consumption habit, the difference was not significant $(P=$ 0.08). It should be noted that if the sample values were higher, the difference would be statistically significant (Figure 1 and Table 3).

\section{Discussion}

In the present study, the cardiac pathology results were significantly correlated with age, type of drug used, and blood lead level. Contrary to the public opinion about the effect of opium, the blood lead level was associated with the increased incidence of atherosclerosis in the cardiovascular system (12).

Lead poisoning due to the use of opium is one of the major health problems in Iran (13). In a study conducted by Mesry et al (1) in Mashhad, Iran, in 2015, it was found that the average level of lead was notably high among opium users. This finding was also confirmed in a study by Dadpour et al in eastern regions of Iran. In another study, the condition of three patients with lead poisoning improved after opium discontinuation (3). Children can also be affected by lead poisoning both in the embryo and during infancy, with a peak reported at 6-24 months of age. Lead encephalopathy is a major complication of acute lead poisoning, which can result in neurological complications and even death $(14,15)$.

Some studies have shown that chronic poisoning is associated with hypertension. It is also believed that the high blood pressure in chronic lead toxicity is related to an increase in the vascular tone $(16,17)$. The results of patients with chronic lead poisoning indicated a reduction in the neuronal activity and a delay in the conductivity of the cardiac system. Also, abnormal liver function in individuals using lead-contaminated food has been reported, although it is a rare finding (18-20). Moreover, among lead-poisoned addicts, biliary colic was reported. In these patients, biliary violation, increased liver enzymes, and abdominal pain were attributed to lead poisoning from an etiological point of view. Therefore, it is important to measure the blood lead level in drug users by atomic absorption spectrometry as the gold standard (21-23).

Our results showed that men were more likely to use drugs than women, and the most common symptoms were abdominal pain with anemia and CNS complaints. Among these patients, blood pressure was $>100 \mathrm{~mm} \mathrm{Hg}$, and the blood lead level was $>25 \mathrm{mic} / \mathrm{dL}$ in some cases and $>200 \mathrm{mic} / \mathrm{dL}$ in seven patients. It should be noted that lead poisoning must be considered in the differential diagnosis of individuals with complaints of abdominal pain and anemia. Besides, the blood lead level needs to be examined, especially among drug/opium users in Iran.

\section{Conclusion}

Lead poisoning does not cause any specific pathological changes in the liver, heart, brain, lung, or kidney tissues; however, these non-specific changes, alone or together, can lead to death.

\section{Ethical issues}

The Ethics Committee of Shahid Beheshti University of Medical Sciences approved this study (ethics code: IR.SBMUMED.REC.1396.361). The patients' confidentiality was maintained by excluding their names when reporting the results.

\section{Authors' Contributions}

All authors read and approved the final manuscript. SMA performed data collection and wrote the manuscript. FN, $\mathrm{DN}$ and $\mathrm{BM}$ contributed to the critical revision, drafting of the manuscript, study design, data analysis, and data interpretation.

\section{References}

1. Mesri M, Valizadegan G, Najari F, Baradaran I, Najari D. Investigation of the clinical signs and symptoms of lead poisoning in patients referred to Baqiyatallah hospital, Tehran, Iran in 2016-2017. J Toxicol Cur Res 2019; 3: 006. doi: 10.24966/tcr-3735/100006.

2. Najari F, Alizadeh-Ghamsari A, Vahabzadeh M, Dadpour B, 
Mousavi SR, Baradaran Kayal I. A study of the importance of clonus symptoms in patients with tramadol poisoning. J Toxicol 2017; 2017: 2151536. doi: 10.1155/2017/2151536.

3. Dadpour B, Hatami Z, Liaghat A, Eshraghi A, Najari F, Najari D. Assessment of QT dispersion in electrocardiogram of patients with acute poisoning of methadone. Tehran University Medical Journal 2019; 77(7): 453-7.

4. Schwartz BS, Lee BK, Lee GS, Stewart WF, Lee SS. Associations of blood lead, dimercaptosuccinic acidchelatable lead, and tibia lead with neurobehavioral test scores in South Korean lead workers. Am J Epidemiol 153: 453-464.

5. Shabani M, Nasiri M, Aminzadeh Z, Hassanian Moghaddam H. A Challenge between Central Nervous System Infection and Lead Toxicity: Opioid Case Reports from Iran. Iran J Med Sci. 2019;44(2):168-171.

6. Ghane T, Zamani N, Hassanian-Moghaddam H, Beyrami A, Noroozi A. Lead poisoning outbreak among opium users in the Islamic Republic of Iran, 2016-2017. Bull World Health Organ 2018; 96(3): 165-72. doi: 10.2471/blt.17.196287.

7. Moghadam HK, Rezaiyan MK, Afshari R (eds). Blood lead levelsin opium addicts in Mashhad, Iran. Clin Toxicol 2014;52:375-6.

8. Arnold J, Morgan B. Management of lead encephalopathy with DMSA after exposure to lead-contaminated moonshine. J Med Toxicol 2015; 11(4): 464-7. doi: 10.1007/ s13181-015-0493-9.

9. Fernández S, Pollio GA, Domínguez V, Nogué S, Torra M, Cardellach F. Outbreak of lead poisoning associated with Ayurvedic medicine. Med Clin (Barc) 2015; 144(4): 166-9. doi: 10.1016/j.medcli.2013.09.048.

10. Madan K, Sharma PK, Makharia G, Poojary G, Deepak KK. Autonomic dysfunction due to lead poisoning. Auton Neurosci 2007; 132(1-2): 103-6. doi: 10.1016/j. autneu.2006.10.002.

11. Bjørklund G, Mutter J, Aaseth J. Metal chelators and neurotoxicity: lead, mercury, and arsenic. Arch Toxicol 2017; 91(12): 3787-97. doi: 10.1007/s00204-017-2100-0.

12. Walter KM, Bischoff K, de Matos R. Severe lead toxicosis in a lionhead rabbit. J Med Toxicol 2017; 13(1): 91-4. doi: 10.1007/s13181-016-0597-x.

13. Najari F, Sheikhveisi Z, Baradaran Kayal J. Variations of coronary arteries in cadavers referred to Tehran forensic medicine organization. J Clin Anal Med 2018; 9(2): 125-7. doi: $10.4328 /$ jcam.5502.

14. Xiang Y, Bai Z, Zhang S, Sun Y, Wang S, Wei X, et al. Lead adsorption, anticoagulation and in vivo toxicity studies on the new magnetic nanomaterial $\mathrm{Fe}(3) \mathrm{O}(4) @ \mathrm{SiO}(2) @$ DMSA as a hemoperfusion adsorbent. Nanomedicine 2017; 13(4): 1341-51. doi: 10.1016/j.nano.2017.01.007.

15. van Eijkeren JC, Olie JD, Bradberry SM, Vale JA, de Vries I, Clewell HJ 3rd, et al. Modeling the effect of succimer (DMSA; dimercaptosuccinic acid) chelation therapy in patients poisoned by lead. Clin Toxicol (Phila) 2017; 55(2): 133-41. doi: 10.1080/15563650.2016.1263855.

16. Radfar SR, Nematollahi P, Farhoudian A, Noroozi A. Lead Poisoning among Opium Users in Iran: A Possible New Emerging Epidemic in the Region. Iran J Public Health. 2017;46(8):1152-1153.

17. Lifshitz M, Hashkanazi R, Phillip M. The effect of 2,3 dimercaptosuccinic acid in the treatment of lead poisoning in adults. Ann Med 1997; 29(1): 83-5. doi: 10.3109/07853899708998747.

18. Kianoush S, Sadeghi M, Balali-Mood M. Recent advances in the clinical management of lead poisoning. Acta Med Iran 2015; 53(6): 327-36.

19. Flora SJ, Pachauri V. Chelation in metal intoxication. Int J Environ Res Public Health 2010; 7(7): 2745-88. doi: 10.3390/ijerph7072745.

20. Hayatbakhsh MM, Oghabian Z, Conlon E, Nakhaee S, Amirabadizadeh AR, Zahedi MJ, et al. Lead poisoning among opium users in Iran: an emerging health hazard. Subst Abuse Treat Prev Policy 2017; 12(1): 43. doi: 10.1186/ s13011-017-0127-0.

21. Farzaneh E, Habibzadeh A, Mehrpour O. Lead toxicity among oral opium addicts with abdominal pain: a case series of 17 cases. Indian J Forensic Med Toxicol 2017; 11(2): 22-5. doi: 10.5958/0973-9130.2017.00057.3.

22. Najari F, Ramazannejad P, Ahmadi A, Amini Z. Epidemiological study of poisoning in patients referring educational and clinical center of Ayatollah Kashani hospital, Shahrekord (West of Iran) throughout 2008-2014. Int J Med Toxicol Forensic Med 2016; 6(3): 121-7. doi: 10.22037/ijmtfm.v6i3(Summer).11262.

23. Alizadeh Ghamsari A, Dadpour B, Najari F. Frequency of electrocardiographic abnormalities in tramadol poisoned patients; a brief report. Emerg (Tehran) 2016; 4(3): 151-4.

24. Mostafazadeh B, Kamaloddini MH, Najari F. Study of death certificates and burial permit with the criteria of the world health organization and the ministry of health and medical education in Tehran during 2013-2014: brief report. Tehran University Medical Journal 2017; 75(6): 457-62. 